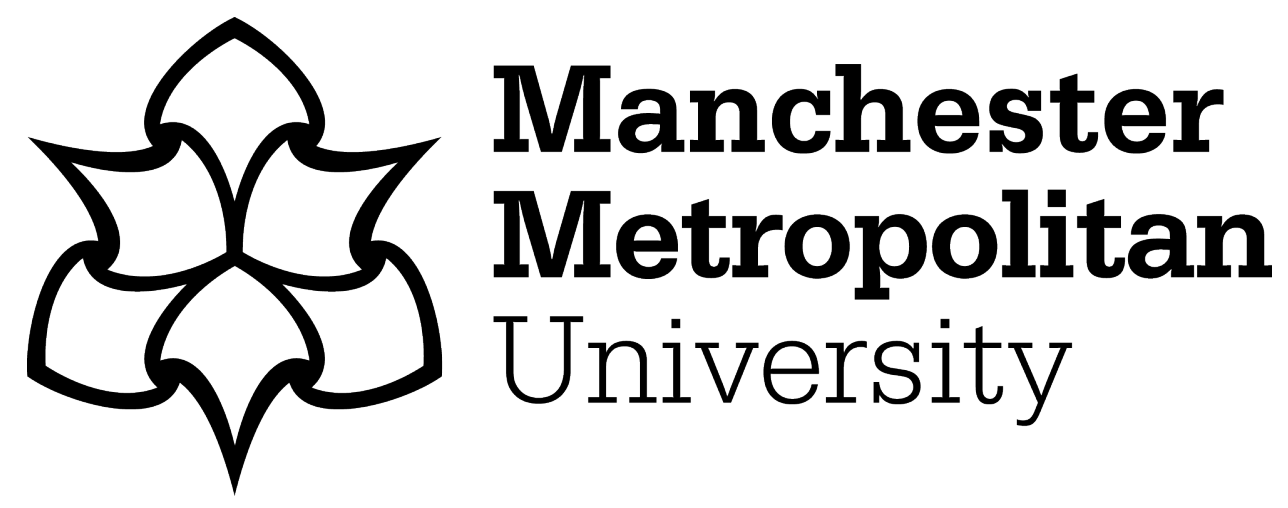

Cook, WAJ (2019) The Effect of Personalised Weight Feedback on Weight Loss and Health Behaviours: Evidence from a Regression Discontinuity Design. Health Economics, 28 (1). pp. 161-172. ISSN 1057-9230

Downloaded from: https://e-space.mmu.ac.uk/621647/

Publisher: Wiley

DOI: https://doi.org/10.1002/hec.3829

Please cite the published version 


\section{The effect of personalised weight feedback on weight loss and health behaviours: Evidence from a regression discontinuity design}

Abstract: Using a regression-discontinuity approach on a UK longitudinal dataset, this research analyses whether personalised weight feedback resulted in individuals losing weight over a period of between 2 and 7 years. The analysis presented here finds that being told one was 'overweight' had, on average, no effect on subsequent weight loss, however being told one was 'very overweight' resulted in individuals losing, on average, approximately $1 \%$ of their bodyweight. The effect of feedback was found to be strongly moderated by household income, with those in higher income households accounting for seemingly all of the estimated effect due, in part, to increased physical activity. These findings suggest that the provision of weight feedback may be a cost effective way to reduce obesity in adults. They do however also highlight that the differential response to the provision of health information may be a driver of health inequalities and that the provision of feedback may bias longitudinal health studies.

Keywords: feedback, health information, obesity, regression discontinuity 


\section{Introduction}

The proportion of adults who are obese is increasing in most developed countries and this is contributing to the increased prevalence of chronic health conditions such as heart disease, diabetes and cancer (Must et al, 1999; Cawley, 2015). The economic costs of obesity include the costs to health services to treat and manage these conditions (Wang et al, 2011), as well as the adverse labour market outcomes experienced by obese adults (Averett, 2014). Economic analysis of the causes of obesity typically focuses on time inconsistent preferences and imperfect information in food purchase and consumption, which gives rise to policy responses around economic incentives and food labelling regulation, approaches that have a mixed record of effectiveness (Cawley, 2015).

A relatively unexplored cause of obesity is that of individuals who are imperfectly informed with regards to their own weight status. Aggregate measures of what is considered a 'healthy' weight have shifted upwards over time and declining proportions of people who are overweight are correctly recognising themselves as being so (Johnson et al, 2008; Johnson et al, 2014). This 'weight misperception' may be important in explaining why overweight individuals do not take action to lose weight (Duncan et al, 2011 ) as those who perceive themselves as overweight make less weight gain and lose more weight over time (Lynch et al, 2009; Inoue et al, 2010). Correcting weight misperceptions through personalised weight feedback therefore has been identified as a possible method by which public policy can encourage weight loss behaviour (Duncan et al., 2011; Yaemsiri et al 2011; Johnson et al, 2008; Gregory et al, 2008).

While a number of studies report that personalised health feedback is associated with selfreported intention to change (Godino, 2013; Prina and Royer, 2014; Yaemsiri et al, 2011) there is a lack of evidence that it results in actual behaviour change and improved health outcomes (McClure, 2002; Jepson et al, 2010). A related area of research concerns the effects of 
technology that records and analyses individuals' health, diet and exercise (e.g. wearables, apps). The evidence as to the weight loss effects of these technologies is mixed (e.g. Jakicic et al, 2016) and there is a need to understand better how the feedback provided can better induce behaviour change and weight loss (Pagoto et al, 2013).

This study provides evidence that personalised weight feedback can result in weight loss in adults through instigating behaviour change, and thus supports the idea that tackling weight misperception as a cause of excess weight may be a cost-effective policy tool in reducing adult obesity. The evidence presented here is an analysis of the effect of receiving weight feedback that was provided as part of the UK Biobank data collection (see www.ukbiobank.ac.uk for further details of the UK Biobank). This feedback was determined by participants' body mass index ("BMI"; calculated as an individual's weight in kilograms divided by their height in metres squared). UK Biobank participants also received health feedback on their body fat percentage, waist circumference and blood pressure; however, this study focuses in on the effect of the BMI feedback on weight change at follow up. This is because BMI is the most widely used measure of healthy weight and the weight feedback associated with it tends to be easily understood by the general public (Stevens et al, 2008; Hall, 2006; Lorimer et al, 2011).

As the weight feedback provided was based on fixed predetermined thresholds, the sharp regression discontinuity ("RD") design method is implemented to estimate the causal effects of feedback. The results suggest that receiving feedback that one was 'overweight' had, on average, no effect on subsequent weight loss, however receiving feedback that one was 'very overweight' resulted in modest weight loss. This effect was concentrated amongst high-income individuals, a finding consistent with the Grossman (1972) health capital framework that predicts that higher income groups are more likely to act on personal health information (Zhao et al, 2013). It also concurs with studies that link the affordability of healthy food and exercise opportunities to weight loss effort (e.g. Johnston and Lordan, 2014). A series of robustness 
checks are employed that provide assurance of the results. This study has ethics approval via the institutional ethics procedures [Details omitted for double-blind reviewing]. Details of the ethical approval for the UK Biobank data collection are available at http://www.ukbiobank.ac.uk/ethics/.

\section{Method}

\subsection{UK Biobank dataset and feedback rules}

The UK Biobank dataset (Sudlow et al, 2015) contains data on health and personal characteristics of 502,632 individuals collected during 2006-2010 (the 'baseline assessment'). The recruitment of the baseline sample was done via an invitation letter to individuals aged 4069 registered with a National Health Service (NHS) General Practitioner who lived within a 'reasonable' travelling distance of one of the 22 UK Biobank assessment centres, with the sample further stratified by age, gender and postcode level social deprivation to obtain a representative sample. Follow up health data on 20,345 of these individuals (the 'repeat assessment') was collected between 2012 and 2013. The repeat assessment recruitment consisted of inviting all those baseline participants who lived within a 30-mile radius of the UK Biobank Co-ordinating Centre, Stockport, UK. Of the 103,514 invited, 20,345 individuals attended the repeat assessment.

At the baseline assessment, participants completed a touchscreen survey, face-to-face interview and a series of physical measurements at their initial visit. At the end of the visit, participants were provided with a printout of selected measurements and feedback associated with these measurements. Participants did not have their results discussed with them by anyone at the UK Biobank assessment centre and did not have any other contact regarding the feedback subsequent to the visit. The weight feedback rules for participants' BMI are shown in Table 1. 


\section{[Table 1. UK Biobank weight feedback rules]}

The analysis sample in this study is restricted to healthy adults, i.e. those without a longstanding illness, disability or infirmity. This left 13,727 cases in the analysis sample. Descriptive statistics for the analysis sample are shown in Table 2.

\section{[Table 2. Descriptive statistics]}

\subsection{Empirical Strategy}

The causal effect of weight feedback on weight loss and other health outcomes is identified by exploiting the sharp change in treatment status that occurs over the "Overweight" and "Very Overweight" feedback thresholds (BMI=25 and BMI=30 respectively) as detailed in Table1. Estimates of the treatment effect of weight feedback are obtained through implementing the non-parametric 'sharp' RD method of estimating local linear regressions with a triangular kernel using a small window of data (i.e. the bandwidth, ' $h$ ') around the treatment threshold cut-offs. Broadly, this approach is applied in this study by estimating the following (See Imbens and Lemieux, 2008 for a full exposition of the non-parametric RD method):

For observations below the treatment cut-off 'c' (i.e. c- $h<B M I \_b a s e l i n e_{i}<\mathrm{c}$ )

$$
\begin{aligned}
& \text { Outcome }_{i}=\alpha_{0}+\beta_{0}\left(\text { BMI_baseline }_{i}-c\right)+\gamma_{0}\left(\text { Controls }_{i}\right)+\epsilon_{i} \\
& \mathrm{i}=1,2, \ldots . \mathrm{N}^{-}
\end{aligned}
$$

For observations at or above the treatment cut-off, 'c' (i.e. c $\leq B M I \_b a s e l i n e_{i}<\mathrm{c}+h$ )

Outcome $_{i}=\alpha_{1}+\beta_{1}\left(B M I \_\right.$baseline $\left._{i}-c\right)+\gamma_{1}\left(\right.$ Controls $\left._{i}\right)+\epsilon_{i}$

$$
\mathrm{i}=1,2, \ldots . . \mathrm{N}^{+}
$$


Where Outcome $_{i}$ is an outcome measure for individual $i$, BMI_baseline is the BMI measurement at baseline (the 'running variable' in RD parlance) and Controls are a set of control variables. The treatment effect is estimated as the difference between the intercepts in these two regressions, $\hat{\tau}=\hat{\alpha}_{1}-\hat{\alpha}_{0}$, as this corresponds to the difference in predicted values of the outcome variable for treated and non-treated cases either side of the cut-off at the cut off boundary. The Stata program rdrobust (Calonico et al, 2017) is used to produce bias-corrected point estimates with accompanying robust standard errors. The bandwidths for each local linear regression are selected using the optimal data-driven method as per Calonico et al (2014).

\section{Results}

\subsection{Graphical analysis}

Figures $1 \mathrm{a}$ and $1 \mathrm{~b}$ show the scatterplots of the baseline BMI against the percentage change in bodyweight between the baseline and repeat assessment. Those who were initially at lower BMI levels experienced a gain in weight, whereas those with higher levels of BMI lost weight - this is consistent with other studies of weight change of older adults over time (Stenholm et al, 2015). There is little evidence of a discontinuity at the BMI $=25$ cut-off in Figure $1 \mathrm{a}$, however Figure $1 \mathrm{~b}$ indicates that weight loss is noticeably greater for individuals to the right of the BMI=30 cut-off and suggests a causal effect of the 'very overweight' feedback on weight loss. 
Figure 1a- Percentage change in body weight by baseline BMI: $B M I=25$ cut-off

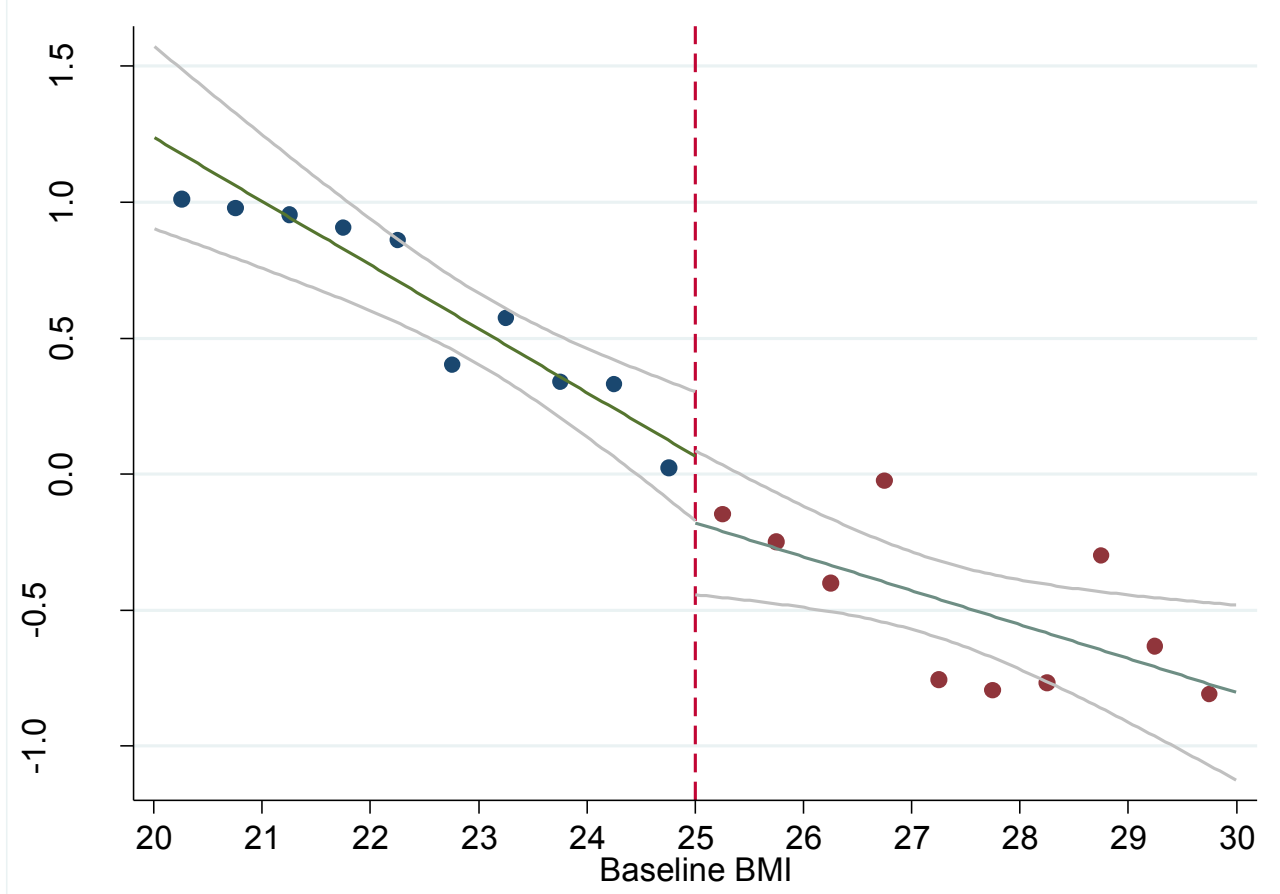

Figure $1 \mathrm{~b}$ - Percentage change in body weight by baseline BMI: BMI=30 cut-off

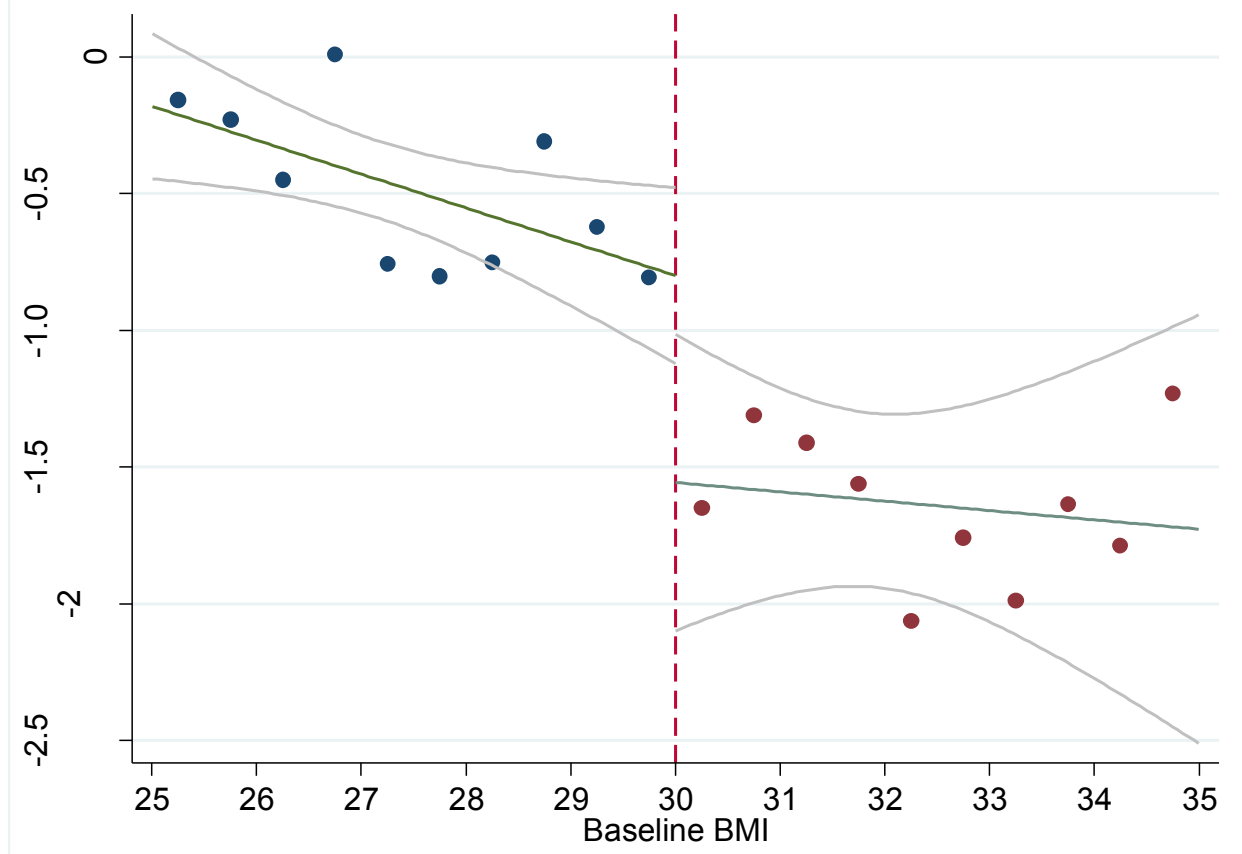

Notes: Figures $1 \mathrm{a}$ and $1 \mathrm{~b}$ plot the percentage change in bodyweight between baseline and repeat assessments against baseline BMI using binned means for each 0.5 BMI unit. The lines indicate a linear fit with corresponding 95\% confidence intervals. 


\subsection{Estimated effects of feedback}

Table 3 presents the local linear regression estimates of the effect of weight feedback on percentage change in bodyweight. Reassuringly for the RD identification strategy employed, the point estimates vary little with the inclusion of controls, but the precision is increased. The estimated effects of the "Overweight" feedback for individuals at the BMI=25 cut-off are negatively signed though are very imprecisely estimated. For those at the BMI=30 cut-off, those receiving feedback that they were 'Very Overweight' lost, on average, just over 1\% of their bodyweight compared to those that were told they were "Overweight".

[Table 3. Local linear regression estimates of the effects of weight feedback] 


\subsection{Robustness checks}

Analysis by the UK Biobank found that those who responded to the follow up invitation had different baseline characteristics to those who were invited but did not respond. Responders tended to be older, healthier and live closer to the assessment centre (UK Biobank, 2014). While differential response to follow up by baseline characteristics does not necessarily bias the RD estimates, it does present the possibility that participants may have a differential response to follow up according to feedback received. If this is the case then the estimated effects of feedback on weight loss might simply be explained by selection bias at the treatment threshold.

To investigate this threat to the validity of the results, a series of robustness checks are implemented to test whether the probability of response to follow up and/or the composition of the follow up sample is affected by adverse weight feedback. First, attendance at the repeat assessment is modelled as an outcome in an RD model using data on all those invited to attend the repeat assessment; second, the continuity of the density around the cut offs is tested using the test proposed by Cattaneo et al (2017). The results from these tests are shown in Table 4 and density plots of participants attending the repeat assessment by baseline BMI are shown in Figure 2. Taken together these results suggest that there is little evidence that the feedback received influenced the probability of attendance at the repeat assessment. Further checks establish whether the composition of the sample displays a discontinuity at the feedback thresholds. These checks are implemented as a series of RD models estimated on the repeat assessment participants using outcomes that should be continuous over the thresholds if there is no selection bias present: baseline anthropometric measures (Table A1), baseline control variables (Table A2), baseline health behaviours (Table A3, and, outcomes at follow up that should not vary as a result of weight loss (Table A4). 
These checks reveal no evidence of discontinuities over the thresholds in these variables and in combination with the density tests indicate that the results in Table 3 are not affected by differential response to follow up according to weight feedback received. Standard RD robustness checks of placebo discontinuities (Table A5), and; sensitivity to bandwidth variation (Table A6) also provide further assurance as to the validity of the results.

[Table 4. Robustness checks for discontinuities in repeat assessment response] 
Figure 2a. Kernel density plot of repeat assessment participants by baseline BMI (BMI=25 cut-off)

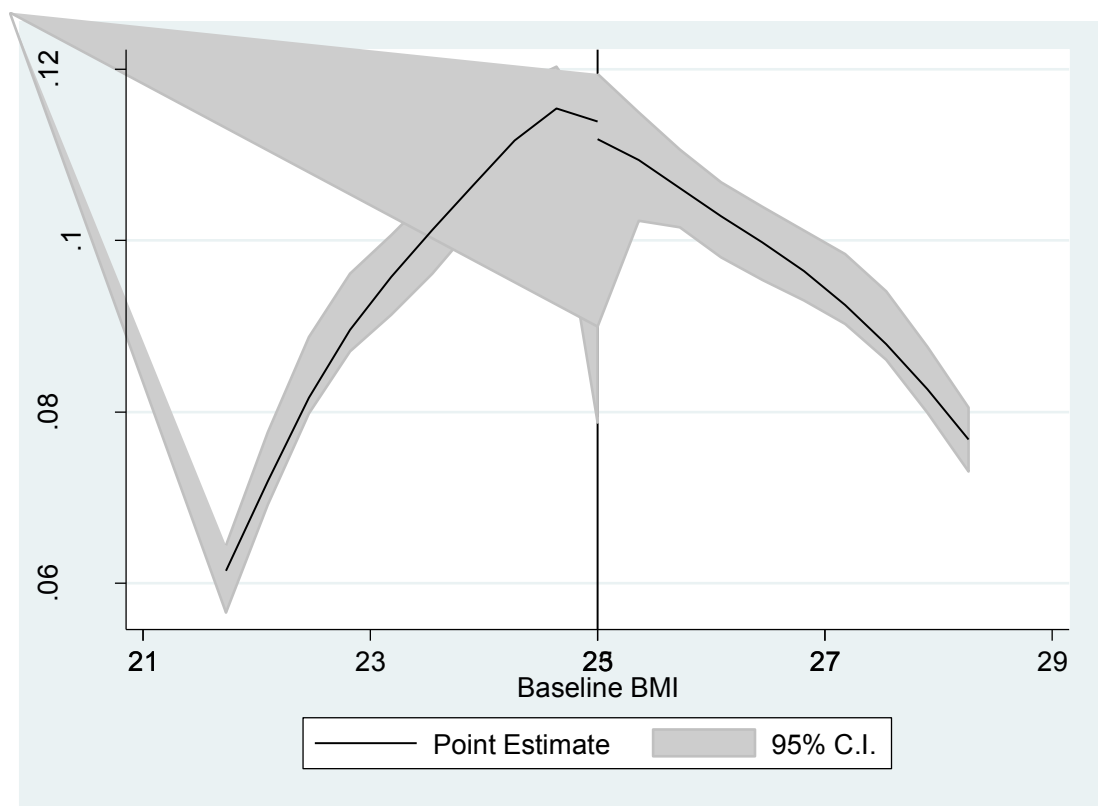

Figure 2 b. Kernel density plot of repeat assessment participants by baseline BMI (BMI=30 cut-off)

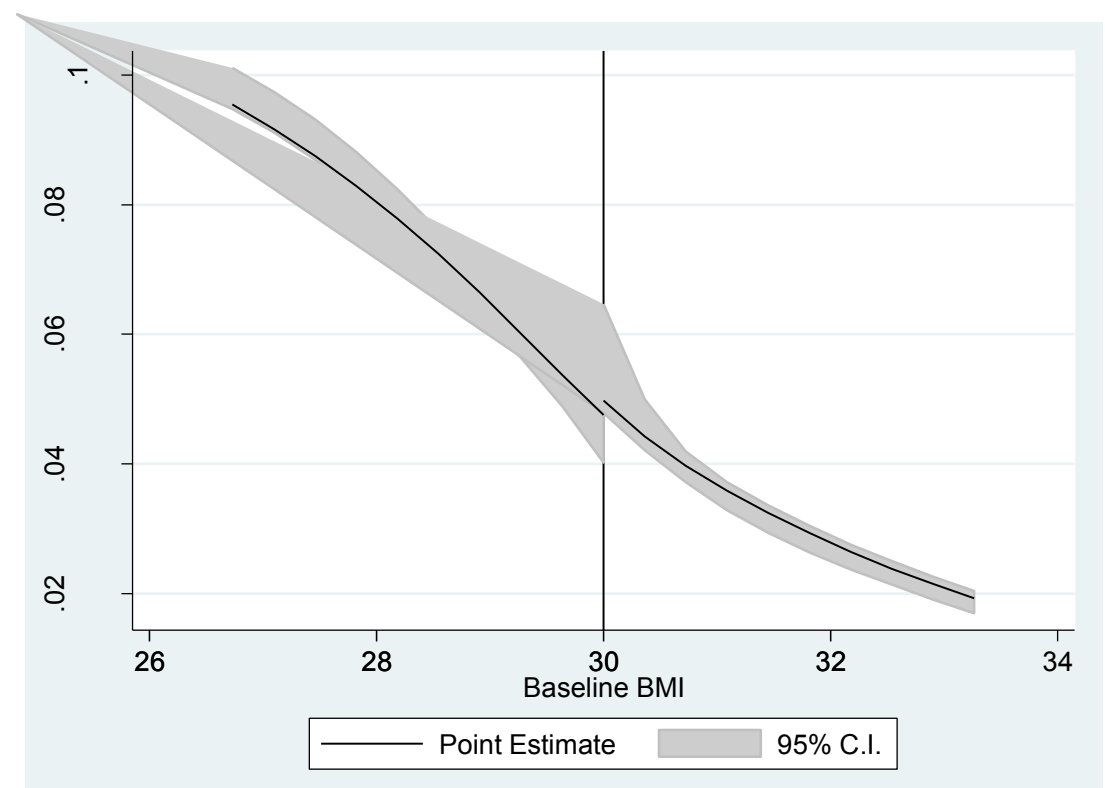




\subsection{Sub group analyses}

As mentioned in the introduction, theory predicts that higher income individuals are more likely to respond to personalised health information and are better able to access weight loss technologies such as healthy food and exercise opportunities. Table 5 presents the analysis of the effect of weight feedback split by household income grouping. The effects of 'Overweight' feedback are mostly small and insignificant across the sub-samples. The subsample analysis of the effects of the 'Very Overweight' feedback however strongly suggests that the effect of this feedback is moderated by household income, with the effect of this feedback only discernible for those living in households with higher incomes. For the high income group, the estimates suggest that the 'Very Overweight' feedback caused, on average, a reduction in bodyweight of approximately $3 \%$, in comparison to those receiving the 'Overweight' feedback. The Cattaneo et al (2017) density tests for each subsample provide further evidence that the results are not affected by differential attendance at the repeat assessment due to the feedback received.

\subsection{Mechanisms}

To test whether the effects of the 'Very Overweight' feedback identified previously can be related to behaviour change, $\mathrm{RD}$ estimates of the effect of this feedback on intentional weight loss and self-reported physical activity variables are provided in Table 6. Most of these estimates for the full analysis sample are positively signed; however, none are statistically significant. Estimating the same models on the sub-sample of individuals in the highest household income category, clearly finds that 'Very Overweight' feedback is associated with increases in physical activity and intentional weight loss, which corresponds with the findings in Table 5 that weight feedback had the greatest effect on the high-income sub-group. 
[Table 5. Heterogeneity in the effects of feedback by household income (Dependent Variable: percentage change in bodyweight)]

[Table 6. Effects of 'Very Overweight' feedback: mechanisms] 


\section{Discussion}

The evidence presented in this article suggests that personalised weight feedback alone, with no further health interventions, can result in modest long-term weight loss. This is in contrast to other studies that have found that even when public health messages are understood they are not acted upon (King et al, 2013). The efficacy of the feedback in this case is possibly due to the personalised nature of the feedback, which would concur with the findings of a systematic review of health behaviour change that found that individualised public health interventions were more effective than mass media campaigns (Jepson et al, 2010). A distinct pattern of heterogeneity is found; those who reside in high income households are most responsive to feedback both in terms of weight loss and in terms of increased physical activity, a finding consistent with Zhao et al (2013) who find similar heterogeneity in response to blood pressure feedback.

While the estimated effects appear small, it should be borne in mind that interventions that have only a small reduction on the average BMI can make a 'significant impact on the burden of chronic disease' at the population level (Kearns et al, 2014). Furthermore these results identify effects on weight loss over a period of between 2 and 7 years, this is in contrast to the poor record of weight loss incentives in effecting long term behaviour change (Royer et al, 2015).

This study also contributes to the understanding of whether the provision of feedback in longitudinal health studies affects the subsequent behaviours of participants. This is an area for which there is extremely limited knowledge (Lorimer et al, 2011), yet has important implications for both the reliability of longitudinal health data and the ethics of whether to provide participant feedback (Jeffery et al, 2005). 


\section{References}

Averett, S. (2014) Obesity and labor market outcomes. IZA World of Labor, 2014:32

Calonico, S., Cattaneo, M., Farrell, M. \& Titiunik, R. (2017): rdrobust: Software for Regression Discontinuity Designs, Stata Journal 17(2): 372-404.

Calonico, S., Cattaneo, M. \& Titiunik, R. (2014): Robust Nonparametric Confidence Intervals for Regression-Discontinuity Designs, Econometrica 82(6): 2295-2326

Cattaneo, M. , Jansson, M. \& Ma, X. (2017) rddensity: Manipulation Testing based on Density Discontinuity, University of Michigan Working Paper [Online] [Accessed on 17th of May 2017] Ma_2017_Stata.pdf

Cawley, J. (2015) An economy of scales: A selective review of obesity's economic causes, consequences, and solutions, Journal of Health Economics, 43, pp244-268

Duncan, D., Wolin K., Scharoun-Lee, M., Ding, E., Warner, E. \& Bennett, G. (2011) Does perception equal reality? Weight misperception in relation to weight-related attitudes and behaviors among overweight and obese US adults, International Journal of Behavioral Nutrition and Physical Activity, 8(20)

Gregory, C., Blanck, H., Gillespie, C., Maynard, L. \& Serdula, M. (2008), Health Perceptions and Demographic Characteristics Associated With Underassessment of Bodyweight. Obesity,16, pp979-986

Godino, J., Watkinson, C., Corder, K., Marteau, T., Sutton, S., Sharp, S., Griffin, S. \& van Sluijs, E. (2013). Impact of Personalised Feedback about Physical Activity on Change in Objectively Measured Physical Activity (the FAB Study): A Randomised Controlled Trial. PLoS ONE, 8(9)

Grossman, M. 1972. On the concept of health capital and the demand for health, Journal of Political Economy 80 (2), pp223-255.

Hall, D. M. B., \& Cole, T. J. (2006). What use is the BMI? Archives of Disease in Childhood, 91(4), pp283-286.

Imbens G. \& Lemieux, T. (2008) . Regression Discontinuity Designs: A Guide to Practice. Journal of Econometrics, 142 (2), pp615-635

Inoue, M. , Toyokawa, S., Inoue, K., Suyama, Y., Miyano, Y., Suzuki, T., Miyoshi,Y.\& Kobayashi, Y. (2010) Lifestyle, weight perception and change in body mass index of Japanese workers: MY Health Up Study, Public Health, 124(9), pp.530-537

Jakicic, J., Davis, K., Rogers, R., et al (2016) Effect of Wearable Technology Combined With a Lifestyle Intervention on Long-term Weight Loss: The IDEA Randomized Clinical Trial. $J A M A, 316(11), \mathrm{pp} 1161-1171$

Jeffery, A., Snaith, R., \& Voss, L. (2005): Ethical dilemmas: feeding back results to members of a longitudinal cohort study. Journal of Medical Ethics 31(3), p153 
Jepson, R., Harris, F., Platt, S. \& Tannahill, C. (2010) The effectiveness of interventions to change six health behaviours: a review of reviews, BMC Public Health, 10, p538

Johnson, F., Beeken, R., Croker, H. \& Wardle, J. (2014) Do weight perceptions among obese adults in Great Britain match clinical definitions? Analysis of cross-sectional surveys from 2007 and 2012 BMJ Open, 4

Johnson, F., Cooke, L., Croker, H. \& Wardle, J. (2008) Changing perceptions of weight in Great Britain: comparison of two population surveys. British Medical Journal, 337(7664), pp. 270-272.

Johnston, D. \& Lordan, G. (2014) Weight perceptions, weight control and income: An analysis using British data, Economics \& Human Biology, vol. 12(C), pp 132-139

Kearns, K., Dee, A., Fitzgerald, A., Doherty., E. \& Perry, I. (2014) Chronic disease burden associated with overweight and obesity in Ireland: the effects of a small BMI reduction at population level, BMC Public Health, 14(143)

King, E., Grunseit A., O'Hara B. \& Bauman A. (2013) Evaluating the effectiveness of an Australian obesity mass-media campaign: how did the 'Measure-Up' campaign measure up in New South Wales? Health Education Research , 28(6) pp1029-39

Lorimer, K., Gray, C., Hunt, K., Wyke, S., Anderson, A. \& Benzeval, M. (2011) Response to written feedback of clinical data within a longitudinal study: a qualitative study exploring the ethical implications, BMC Medical Research Methodology, 11(10)

Lynch, E., Liu, K., Wei, G., Spring, B., Kiefe, C. \& Greenland, P. (2009) The relation between body size perception and change in body mass index over 13 years: the Coronary Artery Risk Development in Young Adults (CARDIA) study. American Journal of Epidemiology, 169 (7), pp857-66

McClure, J. (2002) Are biomarkers useful treatment aids for promoting health behavior change? An empirical review, American Journal of Preventive Medicine, 22(3) pp200-207

Must, A., Spadano, J., Coakley, E., Field, A., Colditz, G. \& Dietz W. (1999) The Disease Burden Associated With Overweight and Obesity, Journal of the American Medical Association, 282(16), pp1523-1529

Pagoto, S., Schneider, K., Jojic, M., DeBiasse, M. \& Mann, D. (2013) Evidence-Based Strategies in Weight-Loss Mobile Apps, American Journal of Preventive Medicine, 45(5), pp576-582

Prina, S. \& Royer, H. (2014) The importance of parental knowledge: Evidence from weight report cards in Mexico, Journal of Health Economics, 37, pp 232-247

Royer, H., Stehr, M. \& Sydnor, J. (2015) Incentives, Commitments, and Habit Formation in Exercise: Evidence from a Field Experiment with Workers at a Fortune-500 Company, American Economic Journal: Applied Economics, 7 (3): 51-84

Stenholm, S., Vahtera, J., Kawachi, I., Pentti, J., Halonen, J., Westerlund, H., Razak, F., Subramanian, S. \& Kivimäki, M. (2015) Patterns of Weight Gain in Middle-Aged and Older US Adults, 1992-2010, Epidemiology, 26 ( 2). pp 165-168 
Stevens, J,. McClain, J. \& Truesdale, K. (2008) Selection of measures in epidemiologic studies of the consequences of obesity, International Journal of Obesity 32, ppS60-S66.

Sudlow, C., Gallacher, J., Allen, N., Beral, V., Burton, P. and Danesh, J., Downey, P., Elliott, P., Green, J., Landray, M., Liu, B., Matthews, P., Ong, G., Pell, J., Silman, A., Young, A., Sprosen, T., Peakman, T. \& Collins, R. (2015) UK Biobank: An Open Access Resource for Identifying the Causes of a Wide Range of Complex Diseases of Middle and Old Age. PLoS Medicine 12(3)

UK Biobank (2014) Repeat Assessment: Participant Characteristics of responders vs. nonresponders, [Online] [Accessed on 28th of March 2017] http://biobank.ctsu.ox.ac.uk/ bbdatan/repeat_assessment_characteristics_v1.pdf

Wang, Y., McPherson, K., Marsh, T., Gortmaker, S. \& Brown, M. (2011) Health and economic burden of the projected obesity trends in the USA and the UK, The Lancet, 378(9793), pp815-825

Yaemsiri, S., Slining, M. \& Agarwal, S. (2011) Perceived weight status, overweight diagnosis, and weight control among US adults: the NHANES 2003-2008 Study, International Journal of Obesity,35, pp1063-1070

Zhao, M., Konishi, Y. \& Glewwe, P. (2013) Does information on health status lead to a healthier lifestyle? Evidence from China on the effect of hypertension diagnosis on food consumption, Journal of Health Economics, 32(2), pp367-385 


\section{Tables}

Table 1. UK Biobank weight feedback rules

\begin{tabular}{|l|c|}
\hline \multicolumn{1}{|c|}{ Baseline BMI measure } & Weight Feedback \\
\hline $\mathrm{BMI}<18.5$ & Underweight \\
$18.5 \leq \mathrm{BMI}<25$ & Good \\
$25 \leq \mathrm{BMI}<30$ & Overweight \\
$\mathrm{BMI} \geq 30$ & Very Overweight \\
\hline
\end{tabular}


Table 2. Descriptive statistics

\begin{tabular}{|l|c|c|c|c|}
\hline \multicolumn{1}{|c|}{ Variable } & Mean & S.D. & Min. & Max. \\
\hline Baseline Covariates & & & & \\
\hline Age & 56.6 & 7.54 & 40 & 70 \\
\hline Male & 0.471 & 0.499 & 0 & 1 \\
\hline Height (cm) & 169.3 & 9.12 & 144 & 200 \\
\hline Years between baseline and repeat assessments & 4.35 & 1.01 & 2 & 7 \\
\hline Neighbourhood Deprivation (Townsend Index) & -2.17 & 2.58 & -6.23 & 8.31 \\
\hline High Income Household & 0.295 & 0.456 & 0 & 1 \\
\hline & & & & \\
\hline & & & & \\
\hline Health Measures at baseline & & & & \\
\hline Weight (kg) & 75.9 & 14.6 & 41.6 & 152.8 \\
\hline BMI & 26.4 & 4.12 & 16.4 & 50.1 \\
\hline & & & & \\
\hline Health Behaviours at baseline & & & & \\
\hline Losing weight & 0.135 & 0.342 & 0 & 1 \\
\hline Walking for pleasure in last 4 weeks & 0.774 & 0.418 & 0 & 1 \\
\hline Exercises (e.g. swimming, cycling, etc.) in last 4 weeks & 0.563 & 0.496 & 0 & 1 \\
\hline Strenuous Sports in last 4 weeks & 0.138 & 0.345 & 0 & 1 \\
\hline & & & & \\
\hline Change in weight between baseline and repeat assessment & & & & \\
\hline Percentage of bodyweight & $-0.278 \%$ & $5.65 \%$ & $-31.6 \%$ & $+37.1 \%$ \\
\hline Kg & -0.306 & 4.51 & -32.3 & +28.1 \\
\hline BMI & +0.0661 & 1.601 & -11.7 & +10.4 \\
\hline
\end{tabular}


Table 3. Local linear regression estimates of the effects of weight feedback

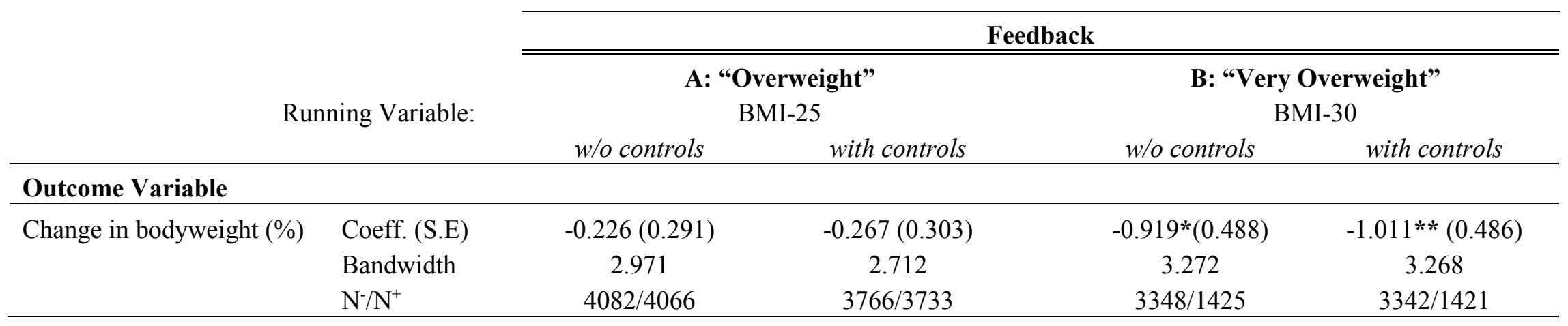

Notes: Robust bias corrected (Calonico et al, 2014) $\mathrm{p}$ values: ${ }^{*}=\mathrm{p}<0.1 ; * *=\mathrm{p}<0.05 ; * * *=\mathrm{p}<0.01 ; \mathrm{N}$ - and $\mathrm{N}^{+}$denote the number of cases within the bandwidth below and above the threshold respectively. Local linear regressions include controls for sex, age at baseline, standing height at baseline, neighbourhood deprivation index, time between baseline and repeat assessment (years). 
Table 4. Robustness checks for discontinuities in repeat assessment response

\begin{tabular}{|c|c|c|c|}
\hline & \multirow[b]{4}{*}{ Running Variable: } & \multirow{2}{*}{\multicolumn{2}{|c|}{ Feedback }} \\
\hline & & & \\
\hline & & A: “Overweight" & B: "Very Overweight" \\
\hline & & BMI-25 & BMI-30 \\
\hline \multirow{3}{*}{$\begin{array}{l}\text { Outcome }=\text { Attended Repeat Assessment } \\
\text { (Sample: invitees to repeat assessment) }\end{array}$} & Coefficient (S.E) & $0.003(0.014)$ & $0.010(0.129)$ \\
\hline & Bandwidth & 1.722 & 3.062 \\
\hline & $\mathrm{N}^{-} / \mathrm{N}^{+}$ & $11,292 / 12,102$ & $16,269 / 8,006$ \\
\hline \multirow[t]{2}{*}{ CJM Density test $\dagger$} & Test Statistic & 0.748 & 1.112 \\
\hline & p-value & 0.454 & 0.266 \\
\hline
\end{tabular}

Notes: Robust bias corrected (Calonico et al, 2014) $p$ values: ${ }^{*}=p<0.1{ }^{* *}=p<0.05 ;{ }^{* * *}=p<0.01$; Local linear regressions include controls for sex, age at baseline, standing height at baseline, neighbourhood deprivation index. $\dagger$ the density test as described in Cattaneo et al (2017), where the null hypothesis is that there is no discontinuity in the density of cases at the cut-offs. 
Table 5. Heterogeneity in the effects of feedback by household income (Dependent Variable: percentage change in bodyweight)

\begin{tabular}{|c|c|c|c|}
\hline & \multirow[b]{4}{*}{ Running Variable: } & & \\
\hline & & \multicolumn{2}{|c|}{ Feedback } \\
\hline & & \multirow{2}{*}{$\begin{array}{c}\text { A: "Overweight" } \\
\text { BMI-25 }\end{array}$} & \multirow{2}{*}{$\begin{array}{c}\text { B: "Very Overweight" } \\
\text { BMI-30 }\end{array}$} \\
\hline & & & \\
\hline \multicolumn{4}{|l|}{ Sub-sample } \\
\hline \multicolumn{4}{|c|}{ Household Income: } \\
\hline \multirow[t]{4}{*}{ High Income } & Coefficient (S.E) & $-0.281(0.642)$ & $-3.383 * * *(1.145)$ \\
\hline & Bandwidth & 2.218 & 2.794 \\
\hline & $\mathrm{N}^{-} / \mathrm{N}^{+}$ & $855 / 794$ & $754 / 328$ \\
\hline & CJM p-value $\dagger$ & 0.783 & 0.622 \\
\hline \multirow[t]{4}{*}{ Middle Income } & Coefficient (S.E) & $-0.010(0.406)$ & $0.446(0.663)$ \\
\hline & Bandwidth & 2.918 & 2.908 \\
\hline & $\mathrm{N}^{-} / \mathrm{N}^{+}$ & $1949 / 2059$ & $1425 / 670$ \\
\hline & CJM p-value & $0.0926 *$ & 0.449 \\
\hline \multirow[t]{4}{*}{ Low Income } & Coefficient (S.E) & $-0.307(1.008)$ & $-1.561(1.342)$ \\
\hline & Bandwidth & 1.726 & 3.656 \\
\hline & $\mathrm{N}^{-} / \mathrm{N}^{+}$ & $304 / 285$ & $461 / 198$ \\
\hline & CJM p-value & 0.208 & 0.791 \\
\hline
\end{tabular}

Notes: As per table 3; † The CJM p-value refers to the p-value from the density test as described in Cattaneo et al (2017), where the null hypothesis is that there is no discontinuity in the density of cases at the cut-offs. The sub-samples by income are determined by the income groups presented to participants in the touchscreen survey and are defined in this study as: high income $=$ annual household income before tax $>£ 51,999$; middle income $=$ annual household income before tax between $€ 18,000$ and $£ 51,999$; low income $=$ annual household income before tax $<£ 18,000$. 
Table 6. Effects of 'Very Overweight' feedback: mechanisms

\begin{tabular}{|c|c|c|c|}
\hline & $\begin{array}{c}\text { Sample: } \\
\text { Running Variable: }\end{array}$ & $\begin{array}{c}\text { Full Analysis Sample } \\
\text { BMI-30 }\end{array}$ & $\begin{array}{c}\text { High Income Households } \\
\text { BMI-30 }\end{array}$ \\
\hline \multicolumn{4}{|l|}{ Outcome Variable (at repeat assessment): } \\
\hline \multirow[t]{3}{*}{ Lost weight in past year (self-reported) } & Coefficient (S.E) & $0.053 *(0.032)$ & $0.133 * *(0.065)$ \\
\hline & Bandwidth & 3.696 & 3.904 \\
\hline & $\mathrm{N}^{-} / \mathrm{N}^{+}$ & $3836 / 1479$ & $1101 / 390$ \\
\hline \multirow[t]{3}{*}{ Walking for pleasure in last 4 weeks } & Coefficient (S.E) & $-0.006(0.034)$ & $0.213 * *(0.088)$ \\
\hline & Bandwidth & 3.515 & 1.892 \\
\hline & $\mathrm{N}^{-} / \mathrm{N}^{+}$ & $3691 / 1480$ & $448 / 246$ \\
\hline \multirow[t]{3}{*}{ Exercises (e.g. swimming, cycling, etc.) in last 4 weeks } & Coefficient (S.E) & $0.028(0.034)$ & $0.065(0.068)$ \\
\hline & Bandwidth & 4.222 & 4.47 \\
\hline & $\mathrm{N} / \mathrm{N}^{+}$ & $4675 / 1635$ & $1336 / 421$ \\
\hline \multirow[t]{3}{*}{ Strenuous sports in last 4 weeks } & Coefficient (S.E) & $0.025(0.024)$ & $0.099 *(0.053)$ \\
\hline & Bandwidth & 3.096 & 3.744 \\
\hline & $\mathrm{N}^{-} / \mathrm{N}^{+}$ & $3124 / 1374$ & $1063 / 392$ \\
\hline
\end{tabular}

Notes: As per table 3 


\section{Appendix}

Table A1 - Robustness Check: Tests for discontinuities in baseline anthropometric measures

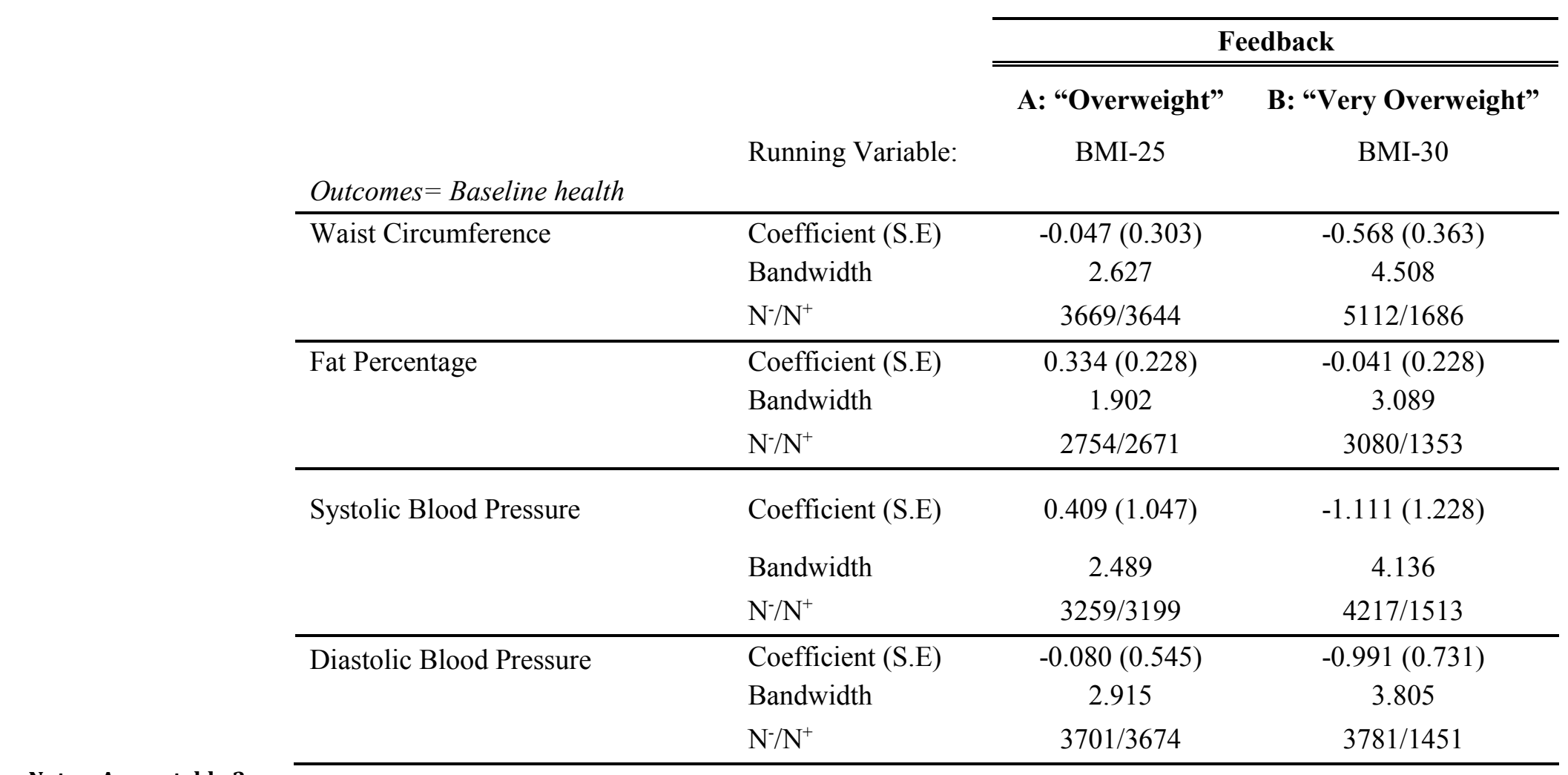

Notes: As per table 3 
Table A2 - Robustness Check: Tests for discontinuities in baseline variables

\begin{tabular}{llcc}
\cline { 3 - 3 } & & \multicolumn{2}{c}{ Feedback } \\
\cline { 3 - 4 } Outcomes & Running Variable: & A: “Overweight" & B: "Very Overweight" \\
& & BMI-25 & BMI-30 \\
\hline Age at baseline & Coefficient (S.E) & $0.041(0.485)$ & $0.760(0.577)$ \\
& Bandwidth & 2.064 & 3.167 \\
& $\mathrm{~N}-\mathrm{N}^{+}$ & $3002 / 2902$ & $3210 / 1394$ \\
\hline Gender (0=female; 1=male) & Coefficient (S.E) & $0.015(0.024)$ & $0.003(0.027)$ \\
& Bandwidth & 1.764 & 3.07 \\
& $\mathrm{~N}-\mathrm{N}^{+}$ & $2607 / 2521$ & $3094 / 1370$ \\
\hline Time between baseline and repeat & Coefficient (S.E) & $-0.077(0.064)$ & $0.105(0.077)$ \\
assessments & Bandwidth & 2.189 & 3.586 \\
& $\mathrm{~N} / \mathrm{N}^{+}$ & $3146 / 3063$ & $3791 / 1497$ \\
\hline Index of neighbourhood deprivation & Coefficient (S.E) & $0.292 *(0.164)$ & $0.180(0.191)$ \\
& Bandwidth & 2.042 & 4.145 \\
& $\mathrm{~N} / \mathrm{N}^{+}$ & $2970 / 2879$ & $4557 / 1623$ \\
\hline Height & Coefficient (S.E) & $0.227(0.395)$ & $0.312(0.417)$ \\
& Bandwidth & 1.967 & 4.172 \\
& $\mathrm{~N} / \mathrm{N}^{+}$ & $2887 / 2781$ & $4594 / 1628$ \\
\hline
\end{tabular}

Notes: As per table 3, though leaving out the corresponding dependent variable of the controls for each model. 
Table A3 - Robustness Check: Tests for discontinuities in baseline health behaviours

\begin{tabular}{llcc} 
& & \multicolumn{2}{c}{ Feedback } \\
\cline { 3 - 4 } & & A: “Overweight” & B: "Very Overweight" \\
& Running & BMI-25 & BMI-30 \\
& Variable: & & \\
\hline Outcomes & & & $-0.004(0.025)$ \\
baseline & Coefficient (S.E) & $0.025(0.021)$ & 3.734 \\
& Bandwidth & 2.271 & $3937 / 1507$ \\
\hline Walking for pleasure in last 4 & Coefficient (S.E) & $0.007(0.025)$ & $-0.016(0.035)$ \\
weeks & Bandwidth & 2.219 & 3.233 \\
& $\mathrm{~N}^{-} / \mathrm{N}^{+}$ & $3104 / 3057$ & $3225 / 1377$ \\
\hline $\begin{array}{l}\text { Exercises (e.g. swimming, } \\
\text { cycling, etc) in last 4 weeks }\end{array}$ & Coefficient (S.E) & $-0.049(0.030)$ & $0.027(0.038)$ \\
& Bandwidth & 2.398 & 3.399 \\
& $\mathrm{~N}^{-} / \mathrm{N}^{+}$ & $3324 / 3277$ & $3455 / 1423$ \\
\hline Strenuous sports in last 4 weeks & Coefficient (S.E) & $-0.017(0.023)$ & $0.028(0.022)$ \\
& Bandwidth & 2.404 & 3.886 \\
& $\mathrm{~N} / \mathrm{N}^{+}$ & $3333 / 3289$ & $4095 / 1530$ \\
\hline
\end{tabular}

Notes: As per table 3. 
Table A4 - Robustness Check: Tests for discontinuities in unrelated outcomes at follow up

\begin{tabular}{|c|c|c|c|}
\hline \multirow[b]{3}{*}{ Outcomes } & \multirow[b]{3}{*}{ Running Variable: } & \multicolumn{2}{|c|}{ Feedback } \\
\hline & & A: "Overweight" & B: "Very Overweight" \\
\hline & & BMI-25 & BMI-30 \\
\hline \multirow[t]{3}{*}{ Serious illness/injury in last 2 years } & Coefficient (S.E) & $0.0138(0.017)$ & $0.031(0.021)$ \\
\hline & Bandwidth & 1.918 & 3.217 \\
\hline & $\mathrm{N}^{-} / \mathrm{N}^{+}$ & $2803 / 2706$ & $3269 / 1399$ \\
\hline \multirow[t]{3}{*}{ Taking prescription medications $\dagger$} & Coefficient (S.E) & $0.019(0.031)$ & $0.003(0.040)$ \\
\hline & Bandwidth & 2.190 & 3.058 \\
\hline & $\mathrm{N}^{-} / \mathrm{N}^{+}$ & $3145 / 3059$ & $3071 / 1367$ \\
\hline \multirow[t]{3}{*}{$\begin{array}{l}\text { Death of a close relative or partner } \\
\text { in last } 2 \text { years }\end{array}$} & Coefficient (S.E) & $-0.019(0.024)$ & $-0.008 \quad(0.032)$ \\
\hline & Bandwidth & 2.546 & 2.921 \\
\hline & $\mathrm{N}^{-} / \mathrm{N}^{+}$ & $3574 / 3526$ & $2889 / 1318$ \\
\hline \multirow[t]{3}{*}{$\begin{array}{l}\text { Marital separation/divorce in last } 2 \\
\text { years }\end{array}$} & Coefficient (S.E) & $-0.002(0.008)$ & $0.017(0.011)$ \\
\hline & Bandwidth & 2.318 & 3.634 \\
\hline & $\mathrm{N}^{-} / \mathrm{N}^{+}$ & $3288 / 3239$ & $3839 / 1498$ \\
\hline \multirow[t]{3}{*}{ Financial difficulties in last 2 years } & Coefficient (S.E) & $-0.0002(0.014)$ & $-0.001(0.019)$ \\
\hline & Bandwidth & 1.952 & 3.034 \\
\hline & $\mathrm{N}^{-} / \mathrm{N}^{+}$ & $2865 / 2747$ & $3037 / 1356$ \\
\hline \multirow{3}{*}{$\begin{array}{l}\text { Distance (metres) travelled to } \\
\text { assessment centre }\end{array}$} & Coefficient (S.E) & $-43.771(1421.2)$ & $312.6(1260.3)$ \\
\hline & Bandwidth & 1.961 & 3.021 \\
\hline & $\mathrm{N}^{-} / \mathrm{N}^{+}$ & $2876 / 2765$ & $3023 / 1356$ \\
\hline
\end{tabular}

Notes: As per table 3 ; $\uparrow$ Medications other than for blood pressure, cholesterol, diabetes and exogenous hormones. 
Table A5 - Robustness Check: Placebo cut-offs (Dependent Variable: percentage change in bodyweight)

\begin{tabular}{llc}
\hline Cut-off= median of 'Very Overweight' & Coefficient (S.E) & $-0.264(1.784)$ \\
& Bandwidth & 0.822 \\
& $\mathrm{~N}-\mathrm{N}^{+}$ & $321 / 259$ \\
\hline & & \\
Cut-off= median of 'Overweight' & Coefficient (S.E) & $-0.504(0.759)$ \\
(BMI=27.110) & Bandwidth & 0.542 \\
& $\mathrm{~N} / \mathrm{N}^{+}$ & $724 / 698$ \\
\hline & & \\
Cut-off= median of 'Good' & Coefficient (S.E) & $-0.236(0.573)$ \\
(BMI=23.200) & Bandwidth & 0.673 \\
& $\mathrm{~N} / \mathrm{N}^{+}$ & $853 / 939$ \\
\hline
\end{tabular}

Notes: As per table 3 
Table A6. Robustness Check: Bandwidth variation (Dependent Variable: percentage change in bodyweight)

\begin{tabular}{|c|c|c|c|}
\hline & \multirow{4}{*}{ Running Variable: } & \multirow{2}{*}{\multicolumn{2}{|c|}{ Feedback }} \\
\hline & & & \\
\hline & & \multirow{2}{*}{$\begin{array}{c}\text { A: “Overweight" } \\
\text { BMI-25 }\end{array}$} & \multirow{2}{*}{$\begin{array}{c}\text { B: "Very } \\
\text { Overweight" } \\
\text { BMI-30 }\end{array}$} \\
\hline & & & \\
\hline \multirow[t]{3}{*}{$0.5 \times$ Optimal Bandwidth } & Coefficient (S.E) & $-0.813(0.566)$ & $-0.682(0.858)$ \\
\hline & Bandwidth & 1.356 & 1.634 \\
\hline & $\mathrm{N}^{-} / \mathrm{N}^{+}$ & $2047 / 1966$ & $1346 / 875$ \\
\hline \multirow[t]{3}{*}{$1.5 \times$ Optimal Bandwidth } & Coefficient (S.E) & $-0.278(0.309)$ & $-0.977^{* *}(0.496)$ \\
\hline & Bandwidth & 4.068 & 4.902 \\
\hline & $\mathrm{N}^{-} / \mathrm{N}^{+}$ & $4845 / 5125$ & $5675 / 1752$ \\
\hline \multirow[t]{3}{*}{$2 \times$ Optimal Bandwidth } & Coefficient (S.E) & $-0.174(0.271)$ & $-0.939 * *(0.434)$ \\
\hline & Bandwidth & 5.524 & 6.536 \\
\hline & $\mathrm{N}^{-} / \mathrm{N}^{+}$ & $5395 / 6109$ & $8113 / 1965$ \\
\hline
\end{tabular}

Notes: As per table 3 